\title{
A Novel Fix- Symbiotic Mutant of Lotus japonicus, Ljsym105, Shows Impaired Development and Premature Deterioration of Nodule Infected Cells and Symbiosomes
}

\author{
Md. Shakhawat Hossain, Yosuke Umehara, and Hiroshi Kouchi \\ National Institute of Agrobiological Sciences, Tsukuba, Ibaraki, 305-8602 Japan; CREST, Japan Science and Technology \\ Agency, 4-1-8 Honcho, Kawaguchi, Saitama 332-0112, Japan
}

Submitted 12 December 2005. Accepted 6 February 2006.

\begin{abstract}
Nitrogen-fixing symbiosis between legume plants and rhizobia is established through complex interactions between two symbiotic partners. To identify the host legume genes that play crucial roles in such interactions, we isolated a novel Fix $^{-}$mutant, Ljsym105, from a model legume Lotus japonicus MG-20. The Ljsym105 plants displayed nitrogen-deficiency symptoms after inoculation with Mesorhizobium loti under nitrogen-free conditions, but their growth recovered when supplied with nitrogen-rich nutrients. Ljsym105 was recessive and monogenic and mapped on the upper portion of chromosome 4. The mutant Ljsym105 formed an increased number of small and pale-pink nodules. Nitrogenase (acetylene reduction) activity per nodule fresh weight was low but retained more than $50 \%$ of that of the wild-type nodules. Light and electron microscopic observations revealed that the Ljsym105 nodule infected cells were significantly smaller than those of wild-type plants, contained enlarged symbiosomes with multiple bacteroids, and underwent deterioration of the symbiosomes prematurely as well as disintegration of the whole infected cell cytoplasm. These results indicate that the ineffectiveness of the Ljsym105 nodules is primarily due to impaired growth of infected cells accompanied with the premature senescence induced at relatively early stages of nodule development. These symbiotic phenotypes are discussed in respect to possible functions of the LjSym105 locus in the symbiotic interactions required for establishment of the nitrogen-fixing symbiosis.
\end{abstract}

Legume plants form root nodules for symbiosis with Rhizobium bacteria to utilize atmospheric nitrogen fixed by the microsymbionts inside the nodules. The ability of symbiotic nitrogen fixation enables the legumes to grow in soil with limited nitrogen supply.

The symbiosis between legume and rhizobia is established through mutual complex interactions between the two symbiotic partners. The "nod inducers," mainly flavonoids exudated from plant roots, stimulate rhizobia to produce lipochitin-oligosaccharide signal molecules, Nod factors that, in turn, elicit nodulation in the host plants. Perception of Nod factors is followed by successive responses, such as root-hair deformation and curling, bacterial invasion into host cells through infection threads, and cortical cell division to form nodule primordia

Corresponding author: Y. Umehara; E-mail: umehara@nias.affrc.go.jp; Telephone: +81-29 838 8377; Fax: +81 298388347 .
(Spaink and Lugtenberg 1994). The rhizobia in nodule infected cells differentiate into bacteroids surrounded by a peribacteroid membrane, and nitrogen fixation takes place.

These successive developmental stages of symbiotic nodule formation are established through highly coordinated actions of the genes of both symbiotic partners. Recent comprehensive analyses using expressed sequence tags accumulated from various legume species revealed that the nodulation process involves global and drastic changes in gene expression in the host legumes (Asamizu et al. 2005; Colebatch et al. 2002, 2004; El Yahyaoui et al. 2004; Kouchi et al. 2004; Ramirez et al. 2005; Tian et al. 2004). These studies have allowed us to identify a number of nodule-specific genes that are activated during the nodulation process. However, the functions of these genes in nitrogen-fixing symbiosis are still largely unknown.

Genetic approaches provide a powerful tool to identify host legume genes that are essential for symbiotic nitrogen fixation. In the past decade, systematic efforts to generate symbiotic mutants have been made for two model legumes, Lotus japonicus and Medicago truncatula (Bénaben et al. 1995; Kawaguchi et al. 2002; Sagan et al. 1995, 1998; Sandal et al. 2006; Schauser et al. 1998; Szczyglowski et al. 1998) and a number of host legume genes required for symbiosis has been isolated in recent years (Ané et al. 2004; Endré et al. 2002; Imaizumi-Anraku et al. 2005; Levy et al. 2004; Limpens et al. 2003; Madsen et al. 2003; Radutoiu et al. 2003; Stracke et al. 2002). Most of these cloned genes are potentially involved in very early steps of the symbiotic signaling pathway that precedes the initiation of the infection process and nodule primordium formation. In contrast, isolation of the host plant genes that are crucial for the interactions in the later stages of symbiosis, such as nodule organogenesis, bacteroid differentiation, and subsequent establishment of functional (nitrogen-fixing) endosymbiosis, are still very limited. Only the LjSstl gene has been reported so far, which encodes a nodule-specific sulfate transporter and is essential for nitrogen fixing symbiosis (Krusell et al. 2005).

We focused our research interests on identification of the genes that play essential roles in such later stages of the symbiosis. Hence, we collected Fix ${ }^{-}$mutant lines of $L$. japonicus that form apparently normal nodules but exhibit very low or no nitrogen-fixation activity, by means of somaclonal mutagenesis through extensive culture of calli or suspension cells followed by regeneration of the plants. Among them, a novel Fix ${ }^{-}$ mutant, Ljsym 105, was isolated from L. japonicus MG-20 'Miyakojima'. In this paper, we describe the detailed characterization of the nodulation phenotypes of the Ljsym105 mutant and 
the current status of our efforts towards the molecular cloning of the Ljsym105 gene. The results will be discussed in respect to possible significance of the Ljsym105 locus in the establishment of functional symbiosis.

\section{RESULTS}

\section{Growth and nodulation phenotypes of the Ljsym105 mutant.}

The Ljsym105 mutant was isolated as showing obvious nitrogen-deficiency symptoms when grown in nitrogen-free medium with inoculation of Mesorhizobium loti. Segregation analysis of the $\mathrm{F}_{2}$ progeny after crossing with wild-type MG-20 plants resulted in 143:38 (wild-type plants/mutants), segregation $\left(\chi^{2}=\right.$ $1.55)$, indicating that the Ljsym105 locus is monogenic and recessive. Analyses that followed were performed on the mutant line established after backcrossing three times with the wild-type plants.

Ljsym105 exhibited stunted shoot and root growth and small chlorotic leaves when grown under symbiotic conditions (Fig. 1). In response to inoculation with Mesorhizobium loti, the Ljsym105 mutants formed small and pale-pink nodules, which thereafter became greenish as a sign of premature senescence (Fig. 1C). Figure 2 shows growth, nodulation, and nitrogen fixation (acetylene reduction activity) phenotypes of Ljsym105 mutants in comparison with the wild-type MG-20 plants. Shoot and root growth of the mutants were both severely impaired over the period of 2 to 6 weeks postinoculation (wpi) of Mesorhizobium loti (Fig. 2A and B). Similarly the nodule fresh weight per plant remained at a much lower level than that of wild-type plants (Fig. 2C), but the mutants formed a slightly larger number of nodules than the wild-type plants (Fig. 2D). Consequently the average fresh weight of individual nodules was less than $30 \%$ of the weight of wild-type nodules. Nitrogenase activity of the nodules at various timepoints was assayed by acetylene reduction activity (ARA). ARA per fresh weight of the Ljsym105 nodules was significantly lower but retained more than $50 \%$ of the ARA of wild-type nodules (Fig. 2E). However, ARA per plant of the mutant remained at significantly lower levels than the wild type over the experimental period (Fig. 2F), reflecting that the growth of the mutant nodules was strongly inhibited (Fig. 2C).

To test if the impaired growth of the Ljsym105 mutants is simply due to nitrogen deficiency by inefficient nitrogen fixation of the root nodules, responses of the mutants to the supply of nitrate were examined (Fig. 3). Though exogenous nitrogen supplies up to $5 \mathrm{mM}$ nitrate did not fully compensate for the impaired growth of Ljsym105, the growth of the mutants supplied with $10 \mathrm{mM}$ nitrate was almost comparable to that of wild-type plants (Fig. 3A). Nodulation of the mutants was inhibited by nitrate at concentrations higher than $1 \mathrm{mM}$, similar to the wild-type plants (Fig. 3B).

Immunoblot analysis using an antiserum against nitrogenase component I proteins indicated that nitrogenase proteins were first detected 8 and 9 days postinoculation (dpi) in the wildtype and Ljsym105 nodules, respectively (Fig. 4). Despite the delay of nitrogenase expression and lower levels of ARA in the mutant nodules, the amounts of nitrogenase proteins relative to nodule total proteins were almost comparable between the wild-type and Ljsym 105 nodules during early stages of nodule formation. However, the mutant nodules exhibited a significantly reduced level of nitrogenase proteins at $21 \mathrm{dpi}$, indicating that premature senescence was a dominant feature of the mutant nodules at this stage.

\section{Cellular structure of the Ljsym105 nodules.}

The central infected zone of wild-type and Ljsym105 nodules were examined by light and electron microscopy. The in- fected zone of wild-type nodules contained large infected cells uniformly packed with bacteroids and small uninfected cells that were almost completely vacuolated at $21 \mathrm{dpi}$ (Fig. 5A). Infected cells were typically 50 to $200 \mu \mathrm{m}$ in diameter, and contained a number of small vacuoles (Fig. 5A and $\mathrm{C}$ ). The most prominent feature of Ljsym105 nodules was a much smaller size of the infected cells compared with those of wild-type nodules (Fig. 5B). In addition, the Ljsym105 nodule infected cells contained one or two large vacuoles instead of many small vacuoles as found in the wild-type nodules, and less densely packed bacteroids appeared to be aggregated (Fig. 5D). These abnormalities in infected cell growth were also observed in 14-day-old nodules formed on the Ljsym105 roots, but aggregation of bacteroids was not obvious at this stage (results not shown). It should be noted that the premature senescence phenotypes, such as bacteroid aggregation and disintegration of the infected cell cytoplasm, were initiated from the central part of the infected zone and spread outward to the infected cells of the peripheral zone (Fig. 5B). Even at $21 \mathrm{dpi}$, the structures of a part of the infected cells remained apparently normal. This could account for the rather high ARA activity of Ljsym 105 nodules in comparison with other Fix ${ }^{-}$mutant nodules described so far (Krusell et al. 2005; Suganuma et al. 2003). In addition, we observed by periodic acid-Schiff staining that a large number of starch granules accumulated in the uninfected cells as well as in the inner cortex of the Ljsym105 nodules (Fig. 6).
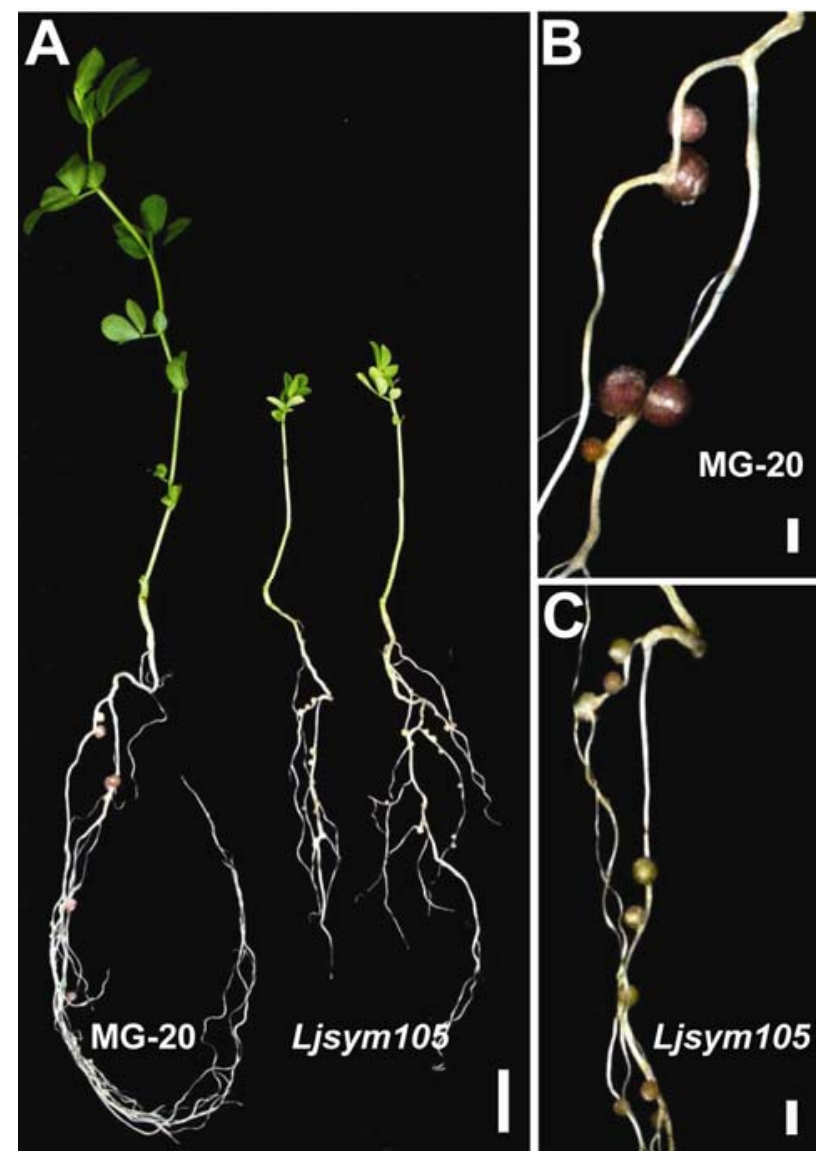

Fig. 1. Growth and nodulation phenotypes of wild-type MG-20 and Ljsym105 plants 4 weeks postinoculation with Mesorhizobium loti. A, Whole plant growth of wild-type (left) and Ljsym105 (middle and right) plants. The mutants show retarded growth, small chlorotic leaves, and small nodules. Note that lower leaves of the mutants were defoliated. Bar $=10 \mathrm{~mm}$. B, Nodules on the roots of wild-type plants. $\mathbf{C}$, Pale-pink and small nodules formed on Ljsym 105 roots. Bars in $\mathbf{B}$ and $\mathbf{C}=2 \mathrm{~mm}$. 
Since the infected cell size in the mutant nodules appeared to be significantly smaller than that of wild-type nodules, we estimated quantitatively the sizes of infected cells together with bacteroid densities (Fig.7). The size of infected cells was represented by areas of individual infected cells collected from independent nodule sections (Fig. 7A). During the period of 9 to $21 \mathrm{dpi}$, infected cell size of wild-type nodules increased rapidly to reach about threefold the initial size, whereas in the mutant nodules it increased much more slowly to reach only 1.8-fold the initial size. As a consequence, the mean section area of Ljsym 105 infected cells at 21 dpi accounted for $39 \%$ of that of the wild type. In contrast, there was no significant dif-
A

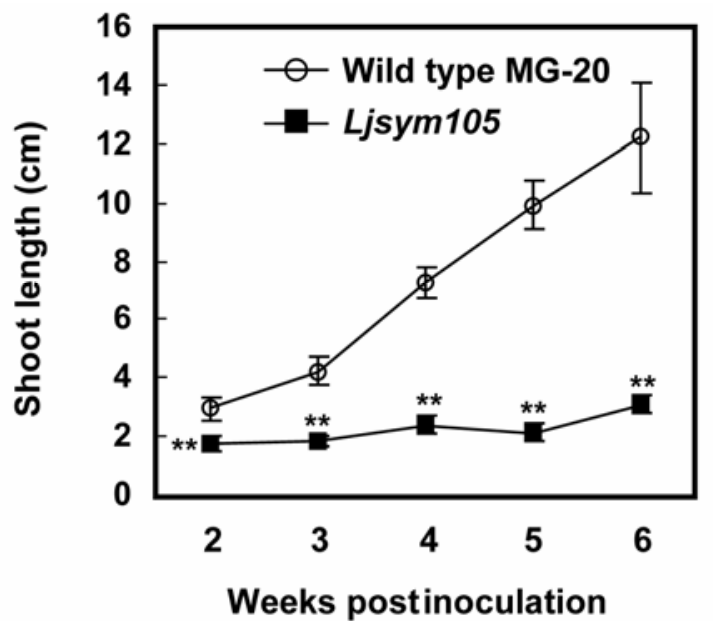

C

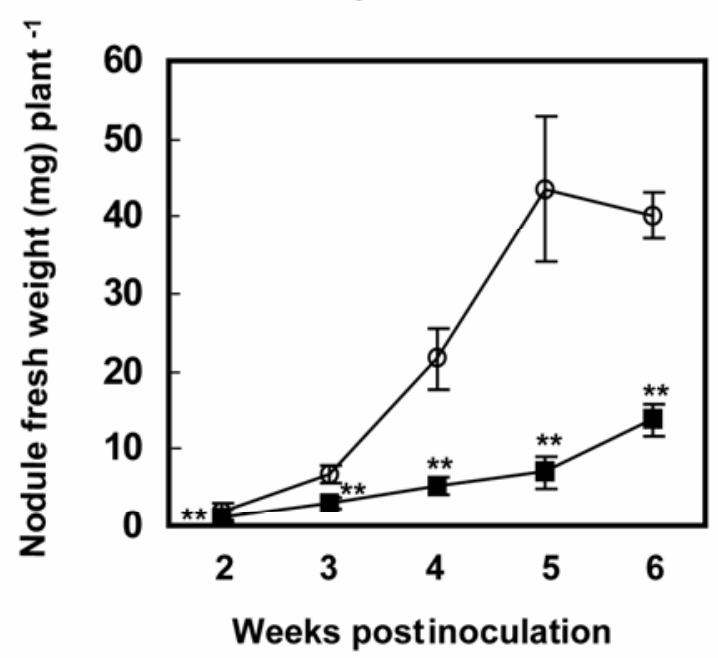

E

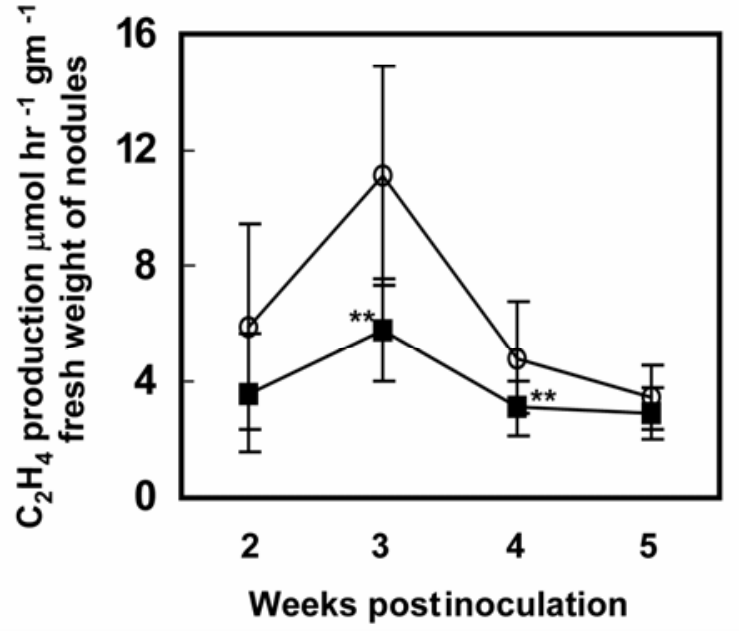

B

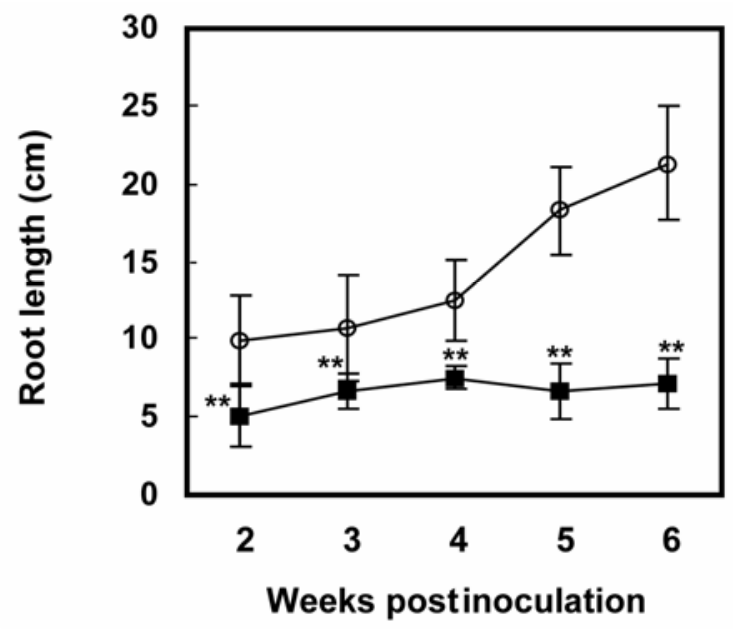

D

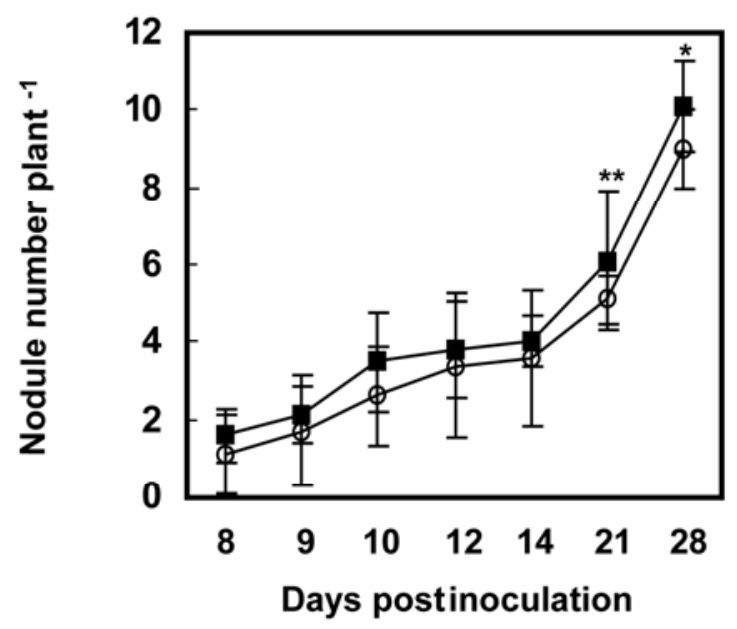

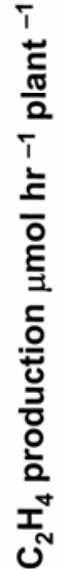

Fig. 2. Timecourses of growth, nodulation, and nitrogenase (acetylene reduction) activities of wild-type and Ljsym105 plants. The plants were grown under symbiotic conditions, and $\mathbf{A}$, shoot and $\mathbf{B}$, root length, $\mathbf{C}$, nodule fresh weight, and $\mathbf{D}$, nodule numbers were determined. Acetylene reduction activities were assayed for individual plants and are shown on the basis of $\mathbf{E}$, nodule fresh weight and $\mathbf{F}$, plant. The data are means of measurements for 10 plants, and vertical bars indicate standard deviations. Asterisks indicate the significance of the difference between MG-20 and Ljsym 105 by $t$-test (* indicates $P<0.05$; ** indicates $P<0.01)$. 
ference in the mean density of bacteroids between wild-type and Ljsym 105 nodules 9 and 14 dpi (Fig. 7B). At 21 dpi, however, bacteroid density was remarkably lower in the mutant infected cells than that in wild-type nodules, in particular, in those with aggregation of the bacteroids and disintegration of cytoplasmic structures.

Figure 8 shows transmission electron micrographs of nodule infected cells. In young developing nodules at $9 \mathrm{dpi}$, the infected cells of wild-type nodules were already densely packed with symbiosomes, most of which contained only a single bacteroid
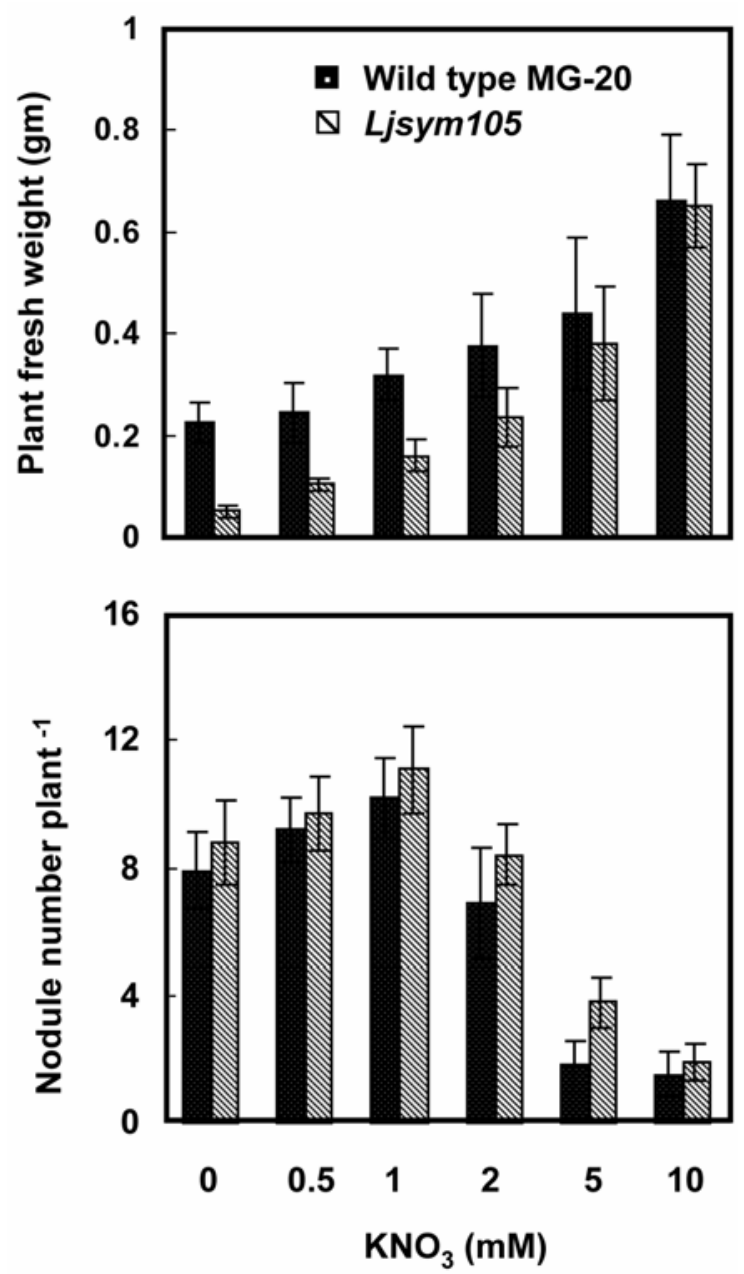

Fig. 3. Effects of nitrate supply on the growth and nodulation of wild-type and Ljsym 105 plants. The plants were inoculated with Mesorhizobium loti and were grown for four weeks with or without the supply of various concentrations of potassium nitrate. The data are averages of measurements for 10 plants, and vertical bars indicate standard deviations.
(Fig. 8A). Peribacteroid (symbiosome) membrane (PBM) was adjacent to bacteroid surface, and symbiosome space with low electron density between PBM and bacteroids was very narrowly defined in most of the symbiosomes. In the Ljsym105 nodule infected cells, symbiosomes enlarged relatively to bacteroids, and hence, the symbiosome space was large and obviously seen (Fig. 8B). In addition, lytic vacuoles were often observed that contained multiple symbiosomes. In the nodules at $14 \mathrm{dpi}$, just after the onset of nitrogen fixation, Ljsym105 infected cells were packed densely with symbiosomes, as in the wild-type nodules, but the symbiosomes were more enlarged and tended to contain larger numbers of bacteroids than those of the wild-type nodules (Fig. 8C and D). Infected cell cytoplasm lost detailed structures and accumulated electron-dense materials. At this stage, some infected cells of Ljsym105 nodules exhibited almost complete deterioration; cytoplasmic structures were disintegrated and abnormally enlarged symbiosomes with many bacteroids as well as naked bacteroids could be seen (Fig. 8E). These observations indicate that premature deterioration of symbiotic structures is initiated at early stages of Ljsym105 nodule development, even though it occurs in only a portion of the infected cells.

\section{Linkage mapping.}

We initiated chromosomal mapping of the Ljsym105 locus towards eventual map-based cloning of the causal gene. A mapping population was generated by crossing Ljsym 105 with wild-type L. japonicus B-129 'Gifu'. A total of 30 simple sequence repeat (SSR) and derived cleaved amplified sequence (dCAPS) markers (Sato et al. 2001) were assessed for cosegregation with Ljsym105 in $50 \mathrm{~F}_{2}$ homozygous recessive mutant plants, in order to identify the location of the gene in the $L$. japonicus genome. As a consequence, we delimited the Ljsym 105 locus within a 1.2-cM region between two SSR markers, TM0126 (24.6 cM) and TM0173 (25.8 cM), on the upper part of chromosome 4 (Sandal et al. 2006). The mapping information together with the results of phenotype analysis strongly suggests that Ljsym105 is a novel Fix ${ }^{-}$locus that is distinct from the Fix ${ }^{-}$loci previously described for $L$. japonicus (Imaizumi-Anraku et al. 1997; Kawaguchi et al. 2002; Schauser et al. 1998; Suganuma et al. 2003; Szczyglowski et al. 1998).

\section{DISCUSSION}

As a result of extensive and systematic efforts in the past decade to isolate various kinds of symbiosis mutants from $L$. japonicus, Kawaguchi and associates (2002) have proposed to classify those symbiotic mutants into three categories according to the stages of nodulation process in which the symbiotic defects are attributed: i) $\mathrm{Nod}^{-}$(nonnodulating) mutants that are defective in very early steps of symbiotic interactions and,

\section{Days postinoculation}

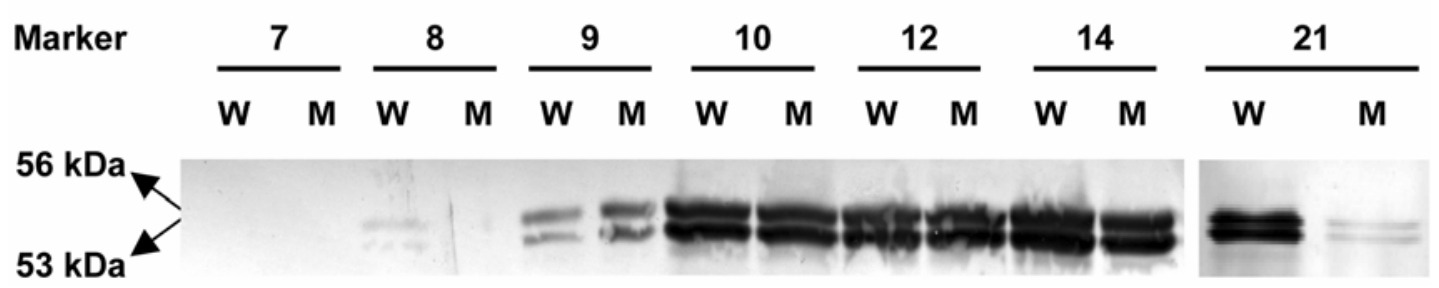

Fig. 4. Western blot analysis of nitrogenase component I proteins in wild-type MG-20 (W) and the mutant Ljsym105 (M) nodules. Nodule extracts (equivalent to $100 \mu \mathrm{g}$ of proteins) were separated by sodium dodecyl sulfate-polyacrylamide gel electrophoresis, were blotted onto a membrane, and were immunodetected by antibodies raised against component I proteins from Rhizobium leguminosarum. 
hence, both rhizobial infection and nodule primordium formation do not occur; ii) Hist $^{-}$(lacking cooperative histogenesis) mutants that fail in either infection-thread formation, its growth, or both, followed by incomplete nodule organogenesis; iii) Fix $^{-}$mutants that form apparently normal nodules with endosymbiotic bacteria but exhibit no or very low nitrogen-fixation activity. Ljsym105 described here is a typical Fix mutant, because it forms morphologically normal nodules with infected cells packed with bacteroids, but nodule nitrogen-fixation activity remained too low to support normal plant growth under symbiotic conditions.

A number of Fix ${ }^{-}$mutants that form ineffective nodules have been isolated from many legume species for both determinate (Imaizumi-Anraku et al. 1997; Suganuma et al. 2003) and indeterminate nodules (Morzhina et al. 2000; Novak et al. 1995; Suganuma et al. 1995, 1998). Among them, senl is one of the most well-characterized Fix ${ }^{-}$mutants of L. japonicus (Kawaguchi et al. 2002; Suganuma et al. 2003). Ineffectiveness of the sen1 nodules is due to a defect in rhizobial differentiation to bacteroids, in which nitrogenase proteins were virtually undetectable, and hence, the sen 1 nodules completely lack nitrogen-fixation activity (Suganuma et al. 2003). On the other hand, another $\mathrm{Fix}^{-}$mutant of L. japonicus, Ljsst1, of which the defective gene has been recently identified as a nodule-specific sulfate transporter, exhibits very low but not negligible nitrogen-fixation activity (Krusell et al. 2005). In com- parison with these $\mathrm{Fix}^{-}$mutants described previously, Ljsym105 nodules show low but substantial activity of nitrogen fixation. Nitrogenase activities per fresh weight of the Ljsym105 nodules accounted for more than half of those of wild-type nodules (Fig. 2E), and the level of nitrogenase expression based on nodule total protein appeared to be only slightly lower than that of wild-type nodules at early stages of nodule formation, as shown by immunoblot analyses (Fig. 4). Nevertheless the nitrogen-fixation activity per plant remained very low, and Ljsym105 plants later develop severe nitrogen deficiency and growth retardation (Figs. 1 and 2F). This is because the infected cells of Ljsym105 as well as the nodule size were significantly smaller than those of wild-type nodules (Fig. 7A). Determinate nodules do not have a permanent meristem, and nodule growth after the onset of nitrogen fixation is mainly achieved by cell expansion of the central infected zone. Enlargement of the infected cells obviously accompanies the proliferation of either symbiosomes, bacteroids, or both (Fig. 7A and B). Severely impaired growth of the infected cells in the Ljsym105 nodules results in a significantly reduced bacteroid population as compared with wild-type nodules and, hence, in no further development of nitrogen-fixation activity during plant growth (Fig. 2F). Thus, it is very likely that ineffectiveness of the Ljsym105 nodules is primarily due to impaired growth of the infected cells rather than defects in bacteroid nitrogenase activity itself.

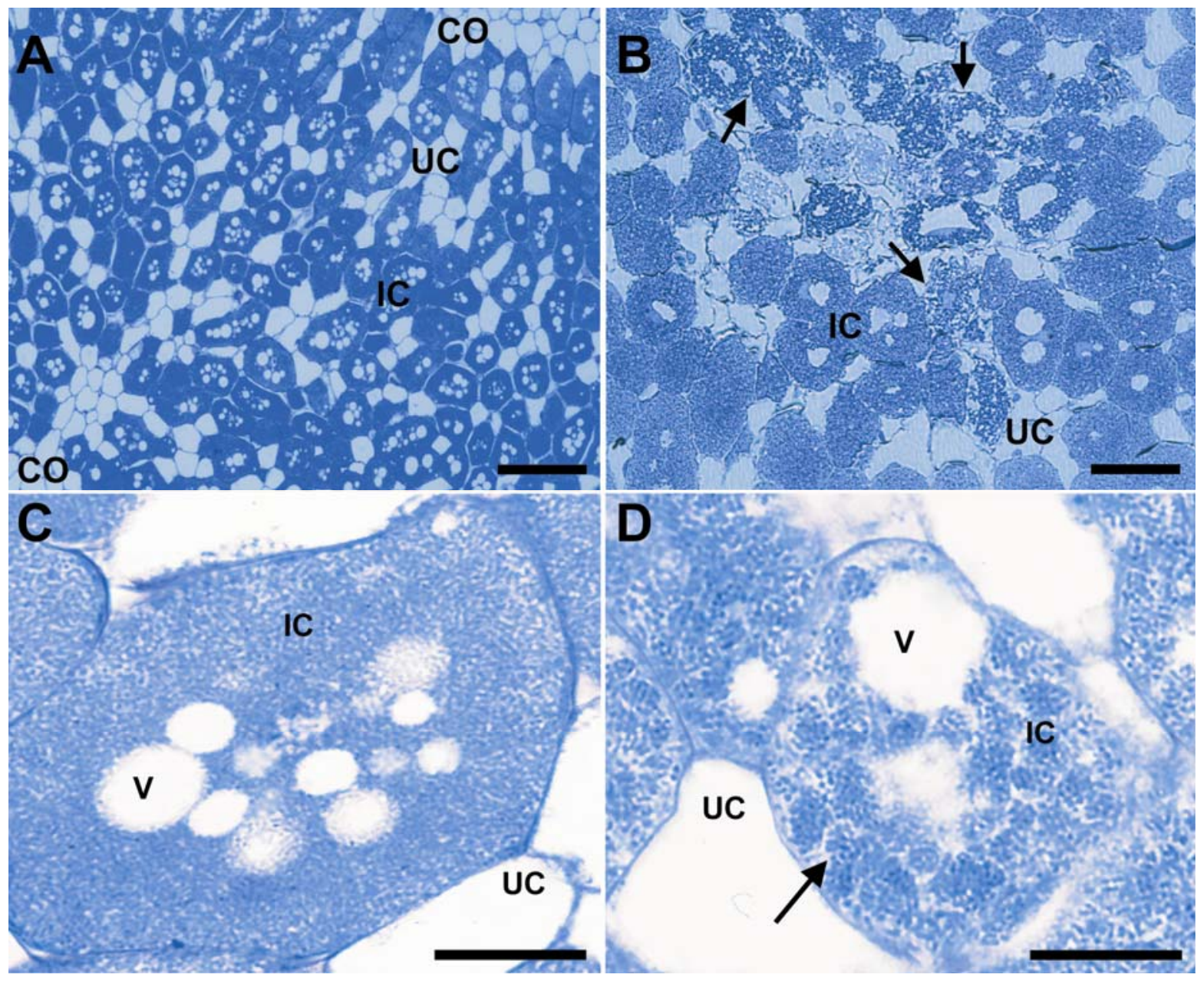

Fig. 5. Light micrographs of the central infected zone of nodules 3 weeks postinoculation with Mesorhizobium loti. A, Wild-type MG-20 showing many large infected cells containing many small vacuoles. B, Ljsym105 nodules. Note smaller size of the infected cells with one or two large vacuoles. Infected cell structures in the central part exhibit obvious disintegration (indicated by an arrow). C, Wild-type nodule infected cells densely packed with bacteroids. D, Disintegrated infected cell of the Ljsym105 nodule with less-dense and aggregated bacteroids (arrow). IC $=$ infected cells, UC $=$ uninfected cells, CO = cortex, and V = vacuoles. Scale bars $=40 \mu \mathrm{m}(\mathrm{A}), 20 \mu \mathrm{m}(\mathrm{B})$, and $10 \mu \mathrm{m}(\mathrm{C}$ and $\mathrm{D})$. 
Biochemical and molecular mechanisms underlying differentiation of Rhizobium bacteria to the symbiotic form, bacteroids, has not been well-studied thus far. A recent transcriptome analysis using a DNA array constructed on the basis of whole genome sequencing of Mesorhizobium loti revealed that bacteroid differentiation involves global and drastic alterations in gene expression in rhizobia (Uchiumi et al. 2004). Differentiation to nitrogen-fixing bacteroids is strictly controlled by interactions with the host nodule cells. Host legume mutants that form $\mathrm{Fix}^{-}$nodules provide a powerful tool to investigate such interactions and the host plant factors required for bacteroid differentiation as well as its maintenance and persistence. In this regard, it is noteworthy that the Ljsym105 nodule infected cells show lytic vacuoles containing symbiosomes as well as enlargement of symbiosomes. These features presumably lead to bacteroid degradation at early stages of nodule development, well before the full expression of nitrogen-fixation activity by bacteroids, even though these features appeared only in a portion of the infected zone (Figs. 5B and 8B). In addition, expression of nitrogenase proteins in endosymbionts does not necessarily imply the full differentiation into bacteroids (Suganuma et al. 2003). Therefore, it cannot be excluded that LjSym105 affects the process of bacteroid differentiation. More detailed analysis of bacteroid differentiation in the Ljsym105 mutant nodules in comparison with that of wild-type nodules is an intriguing subject for the future.

Nodules formed on $\mathrm{Fix}^{-}$mutants exhibit premature senescence in common, such as abnormal or excessive vacuolation, or both, of infected cells, enlargement of symbiosomes, and

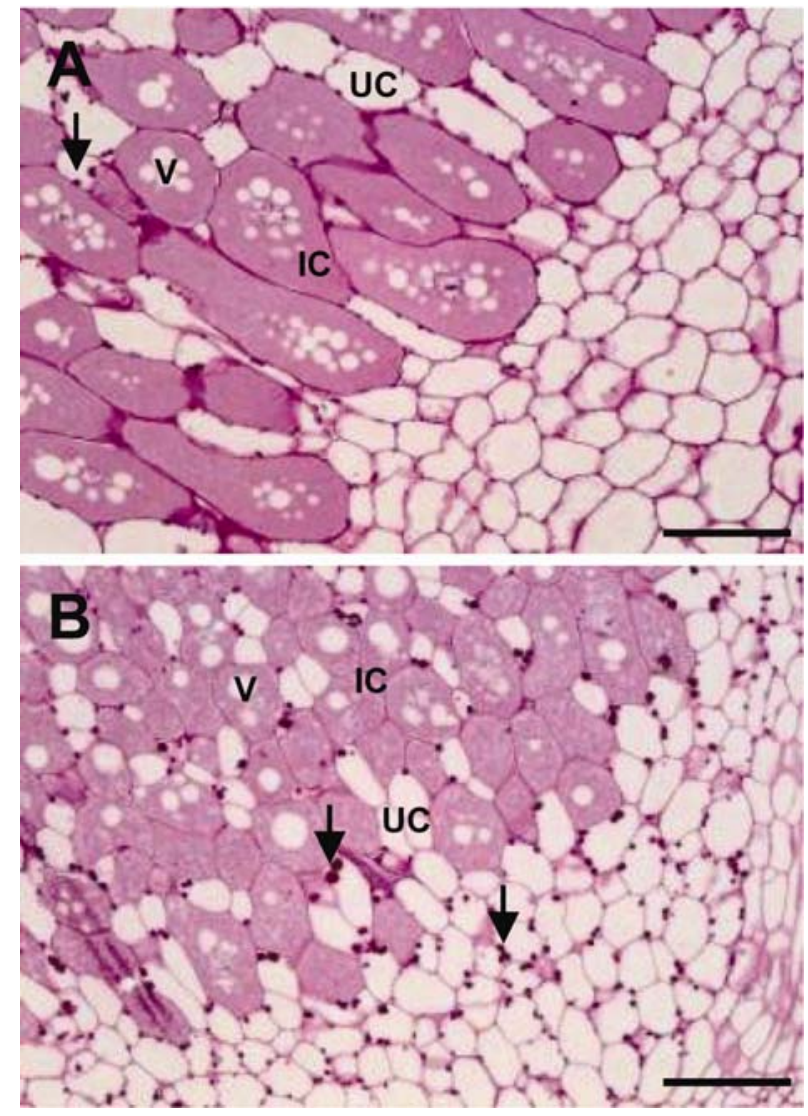

Fig. 6. Light micrographs of wild-type MG-20 and Ljsym105 nodules stained with periodic acid-Schiff. A, A section of wild-type MG-20 nodule showing no or very few starch granules with small size (an arrow). B, A section of Ljsym 105 nodule. Large numbers of starch granules were accumulated in uninfected cells in the central zone as well as in the nodule cortex (indicated by arrows). Scale bars $=40 \mu \mathrm{m}$. disintegration of infected cell cytoplasm. These phenotypes have been more or less observed in most of the Fix $^{-}$mutants isolated from various legume species, as well as ineffective nodules formed by Rhizobium etli CE3 on L. japonicus (Banba et al. 2001). Increase in the number of bacteroids in a symbiosome unit of Ljsym105 nodules as shown in Figure 8D and E has been also found in the sen 1 nodules (Suganuma et al. 2003). Lytic vacuoles (Fig. 8B), which might be a sign of bacteroid degradation, have also been observed in the sst 1 nodules (Krusell et al. 2005). It has been shown that the premature senescence of nodules is not simply due to nitrogen deficiency caused by ineffective nitrogen fixation (Banba et al. 2001). It is more likely that it reflects the activation of a kind of plant defense response to exclude nonfixing or inefficient endosymbionts that confer no benefit to the host plants (Suganuma et al. 2003). However, it should be noted that temporal patterns and the extent of these phenotypes of premature senescence is considerably different between each Fix ${ }^{-}$mutant. Progression of premature senescence in senl nodules is rather slower than Ljsym105 and sst1, despite the fact that sen 1 nodules completely lack nitrogenase activity whereas the latter two retain very low but significant nitrogenase activity. Furthermore, disintegration of infected cells occurs from the proximal part of

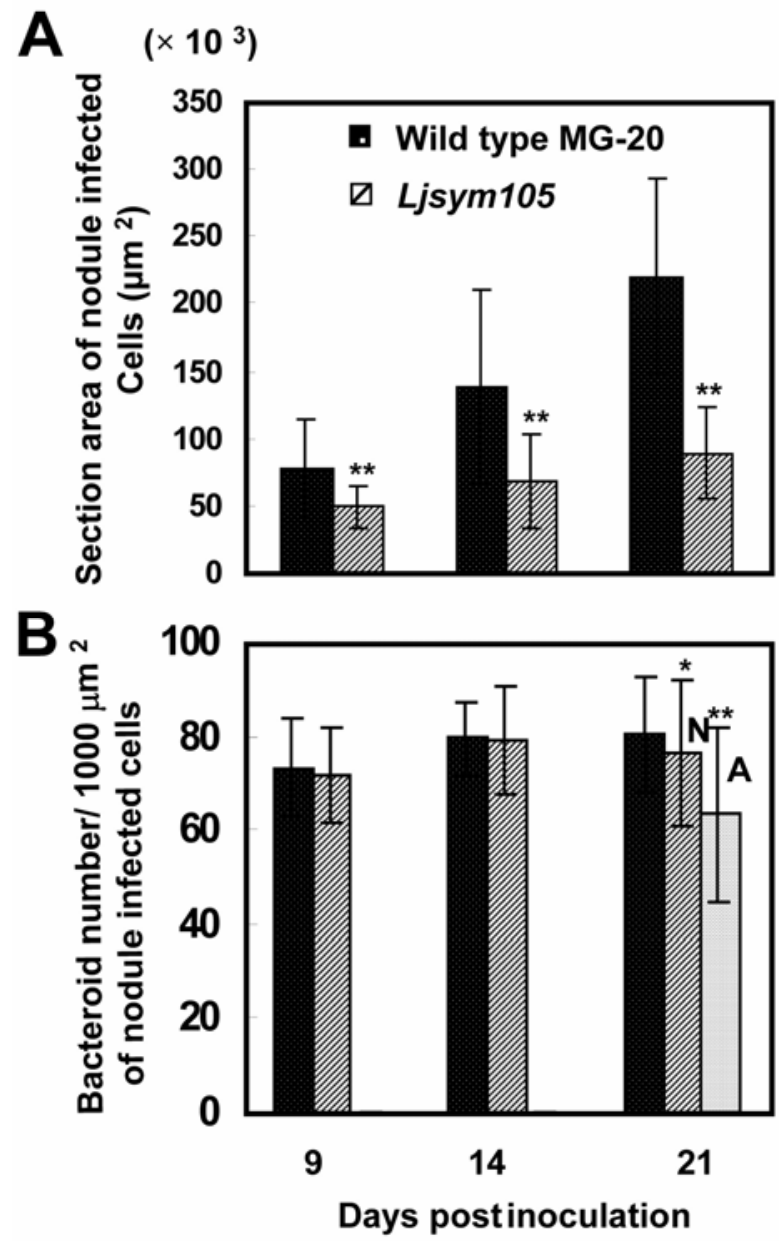

Fig.7. Section areas of $\mathbf{A}$, infected cells and $\mathbf{B}$, the bacteroid density in MG-20 and Ljsym105 nodules. The data are means \pm standard deviation of the measurements of 40 to 80 infected cells collected from 8 and 10 independent nodule sections for MG-20 and Ljsym 105, respectively. $\mathrm{N}$ and A in panel B indicate apparently normal infected cells and those with aggregated or degraded bacteroids, or both, of Ljsym 105 nodules, respectively. Asterisks indicate the significance of the difference between MG-20 and Ljsym 105 by $t$-test (* indicates $P<0.05$; ** indicates $P<0.01$ ). 
the sen1 nodules (Suganuma et al. 2003), while it was initiated very early from the central part of the infected zone in the Ljsym105 nodules (Fig. 5B). These differences in the situation of premature senescence between the Fix ${ }^{-}$mutants are likely to reflect the functions of the defective genes in each mutant, even if they were not directly relevant to premature senescence. More detailed and comparative analysis of the premature senescence phenotypes in a number of Fix mutants of $L$. japonicus may provide important clues to elucidate possible functions and interrelationships of the defective genes in each Fix ${ }^{-}$mutant.

Genetic loci in $\mathrm{Fix}^{-}$mutants are attributed to late stages of symbiotic nodule development, such as the differentiation of Rhizobium bacteria to fully functional (nitrogen-fixing) bacteroids and the organization of metabolic (including transport) functions in the host nodule cells, which are required for nitrogen fixation by the endosymbionts (Suganuma 1999). Although it is too early to speculate the exact functions of the LjSym 105 locus at such a late stage of nodulation, we hypothesize that it is involved in organization of metabolic function in the nodule that is essential for nitrogen fixation by bacteroids as well as either maintenance, further development, or both of symbiosis rather than the possibility that it controls bacteroid differentia- tion itself, as in the case of the sen 1 mutant (Suganuma et al. 2003). Premature senescence of the nodules, as a dominant and common phenotype in many Fix $^{-}$symbiotic mutants, makes it somewhat difficult to assign the possible functions of individual $\mathrm{Fix}^{-}$loci in establishment and persistence of nitrogen-fixing symbiosis on the basis of analyses of their apparent phenotypes. To overcome this, systematic and comparative studies of a number of $L$. japonicus Fix $^{-}$mutants and wild-type nodules in regard to gene-expression profiles of both bacteria and host plants are useful for ordering each $\mathrm{Fix}^{-}$locus within the context of a pathway leading to establishment of fully functional symbiosis. Such further work, by means of the DNA array systems for both Mesorhizobium loti and L. japonicus, is currently in progress in our laboratory as well as efforts towards map-based cloning and molecular characterization of the causal genes of the mutants.

\section{MATERIALS AND METHODS}

\section{Plant materials.}

Generation of mutant lines of Lotus japonicus B-129 'Gifu' and MG-20 'Miyakojima' by means of somaclonal mutagenesis will be described elsewhere (Y. Umehara, unpublished data).

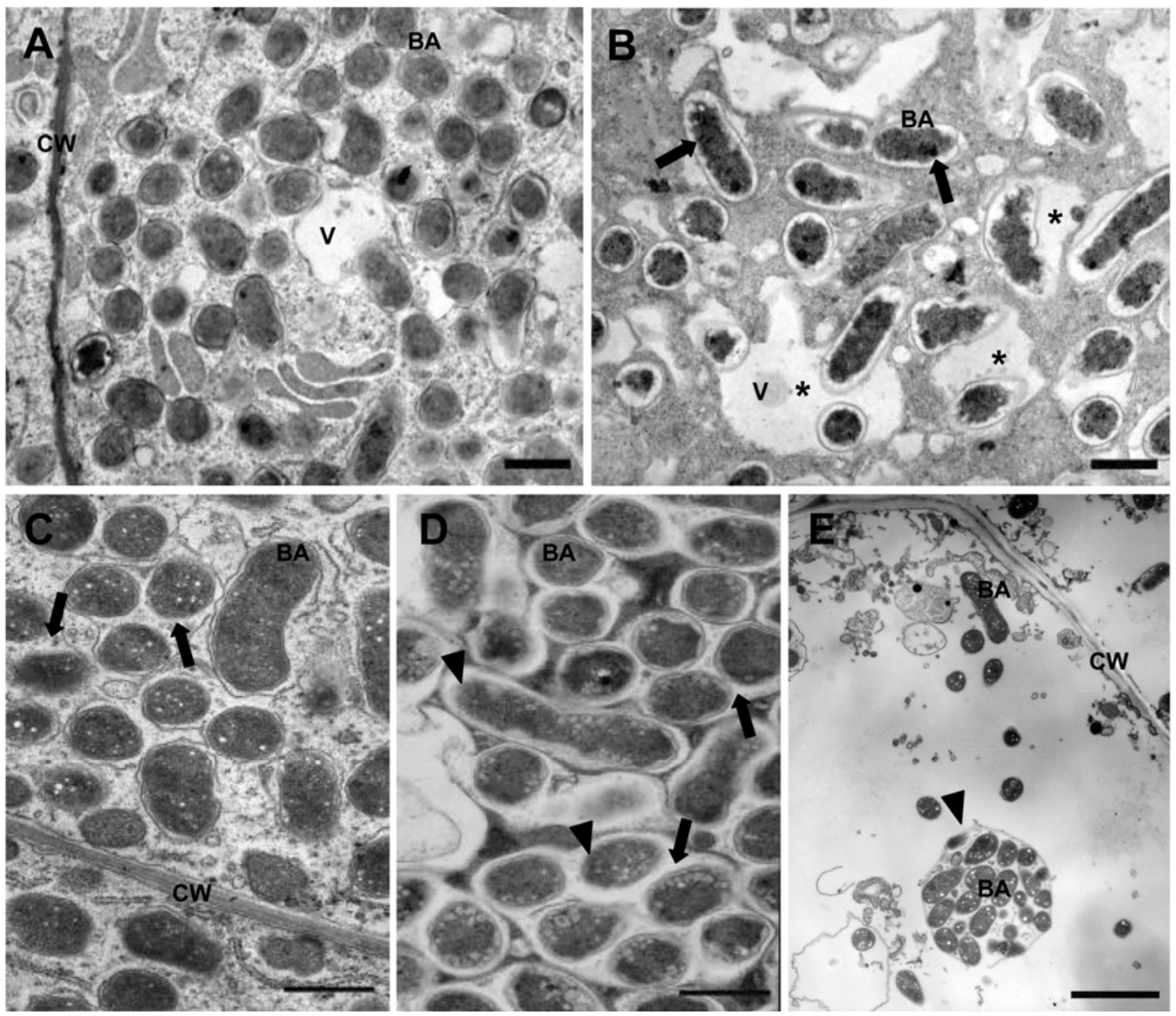

Fig. 8. Transmission electron micrographs of infected cells of wild-type MG-20 and Ljsym 105 nodules. A, Wild-type nodule 9 days postinoculation (dpi). B, Ljsym 105 nodule 9 dpi. Note enlarged symbiosome space (arrows) and lytic vacuoles containing symbiosomes (asterisks). C, Wild-type nodule 14 dpi. Some symbiosomes fused and contain multiple bacteroids (arrows). D, Ljsym105 nodule 14 dpi. Enlarged symbiosomes (arrows) and bacteroids with indistinct surface (arrowheads) can be seen. Note that infected cell cytoplasm was disintegrated. E, Ljsym105 nodule 14 dpi. A number of the infected cells completely lost the integrity of the cytoplasm, and large symbiosomes (arrowhead) and naked bacteroids were observed. $\mathrm{BA}=\mathrm{bacteroid}, \mathrm{V}=\mathrm{vacuole}$, and $\mathrm{CW}=$ cell wall. Scale bars $=1 \mu \mathrm{m}(\mathrm{A}$ to $\mathrm{D})$ and $2 \mu \mathrm{m}(\mathrm{E})$. 
In brief, hypocotyl-derived calli were subjected to extensive in vitro culture for more than five weeks to induce mutation followed by regeneration of plants, according to the procedures described previously (Stiller et al. 1997). A total of 30,000 M2 descendants from the seeds of approximately 800 independent regenerated plants were grown in nitrogen-free medium after inoculation of Mesorhizobium loti Tono and were for the symbiotic defects. By this procedure, we established more than 10 independent lines of symbiotic mutants, and a novel Fix ${ }^{-}$mutant, M202-24 (Ljsym105), was isolated from MG-20 'Miyakojima'.

The seeds of the Ljsym105 mutants and wild-type MG-20 were scarified with pieces of sand paper and were surface-sterilized with $2 \%$ sodium hypochlorite containing $0.02 \%$ Tween20 for $10 \mathrm{~min}$, followed by washing with sterile water. They were germinated and grown for 14 days on $0.8 \%$ (wt/vol) agar containing $1 / 10$-strength B5 mineral medium (Gamborg et al. 1975 ) in a growth cabinet under a 16-h-light and 8-h-dark cycle at $25^{\circ} \mathrm{C}$. Then, the seedlings were transferred to autoclaved vermiculite pots supplied with $1 / 2$-strength $B \& D$ medium with or without $1 \mathrm{mM}$ ammonium nitrate (Imaizumi-Anraku et al. 1997) and were further grown under the same growth conditions. The plants were inoculated with Mesorhizobium loti Tono (Kawaguchi et al. 2002) three days after transplanting to the vermiculite pots.

\section{Acetylene reduction assay.}

An intact plant was placed in a 12-ml glass tube with a rubber cap and was incubated in a water bath at $25^{\circ} \mathrm{C}$. Acetylene ( $1 \mathrm{ml}$ ) was injected into the tube, and the amount of ethylene formed after 20 min was determined by gas chromatography, as previously described (Kouchi et al. 1991).

\section{Immunoblotting.}

Nodules were ground to fine powder under liquid nitrogen and were extracted with modified Laemmli's SDS sample buffer (10\% sodium dodecyl sulfate (SDS), 0.5M Tris-Cl, $\mathrm{pH}$ 6.8, 10\% glycerol, $1 \% \mathrm{BPB}$, and $20 \%$ 2-mercaptoethanol) (Laemmli 1970). Protein concentrations were determined by the modified Lowry's method (Bensadoun and Weinstein 1976). Proteins $(100 \mu \mathrm{g})$ were subjected to SDS-polyacrylamide gel electrophoresis on a $12 \%(\mathrm{wt} / \mathrm{vol})$ polyacrylamide gel and were electro-blotted onto an Immobilon-P membrane (Millipore, Tokyo) according to the manufacturer's instructions. Membranes were reacted with antisera raised against nitrogenase component-I of Rhizobium leguminosarum bv. viceae (Bisseling et al. 1980), followed by detection by anti-rabbit immunoglobulin G (Sigma, St. Louis) conjugated with alkaline phosphatase, using nitroblue tetrazolium chloride and 5-bromo4-chloro-3-indolyl-phosphate (Roche Applied Science, Basel, Switzerland) as substrates.

\section{Light microscopy.}

Nodules on root segments were fixed in $4 \%$ paraformaldehyde and $2.5 \%$ glutaraldehyde in $0.1 \mathrm{M}$ sodium phosphate buffer (pH 7.2) at $4^{\circ} \mathrm{C}$ overnight. Fixed samples were dehydrated through a graded ethanol series and were embedded in Technovit 7100 resin (Kulzer Histo-Technik; Heraeus Kulzer GmbH \& Co., Wehrheim, Germany). Semithin microtome sections ( 1 to $1.5 \mu \mathrm{m}$ thick) were stained with $1 \%$ (wt/vol) toluidine blue in $0.5 \%$ (wt/vol) sodium tetraborate $(\mathrm{pH} \mathrm{9.0)}$ (Imaizumi-Anraku et al. 1997) and were observed with a light microscope. Bacteroid numbers were counted on the microphotographs taken by a microscope equipped with a $100 \times$ oil-immersion objective. ImageJ software ver. $1.34 \mathrm{~s}$ was used for measurements of the infected cell size and bacteroid numbers.

\section{Electron microscopy.}

Fresh nodules were cut to small pieces $(<1 \mathrm{~mm}$ thick) and were fixed in $2.5 \%$ glutaraldehyde and $4.0 \%$ paraformaldehyde in $0.1 \mathrm{M}$ sodium phosphate buffer ( $\mathrm{pH} 7.2$ ) for $3 \mathrm{~h}$ at room temperature and then overnight at $4^{\circ} \mathrm{C}$. After washing extensively in the same buffer, the materials were postfixed in $2.0 \%$ osmium tetraoxide in $0.1 \mathrm{M}$ sodium phosphate buffer $(\mathrm{pH}$ 7.2) for $3 \mathrm{~h}$ at room temperature, were dehydrated through graded ethanol and then acetone series, and were embedded in an epoxy resin (Quetol-812, Nisshin EM Co. Ltd., Tokyo). U1trathin sections were made by an ultramicrotome (UltraCut-R, Leica Microsystems, Tokyo) equipped with a diamond knife (Diatome, Hatfield, PA, U.S.A.). They were poststained with uranium acetate and lead citrate and were observed under a transmission electron microscope (H-7100, Hitachi, Tokyo).

\section{Linkage analysis.}

The mutant Ljsym105 was crossed with L. japonicus 'Gifu' B-129 for mapping studies. A population of $50 \mathrm{~F}_{2}$ individuals with the mutant phenotype and $50 \mathrm{~F}_{2}$ individuals with the wild-type phenotype were used for rough mapping of the Ljsym105 locus. A trifoliate leaf from each of the $\mathrm{F}_{2}$ plants was used to extract genomic DNA for polymerase chain reaction (PCR), using a small-scale modified CTAB method (Murray and Thompson 1980). To map the Ljsym105 locus, SSR and dCAPS markers (Hayashi et al. 2001; Nakamura et al. 2002; Sato et al. 2001) were used. PCR was carried out in $10-\mu$ reaction mixtures that contained $30 \mathrm{ng}$ of genomic DNA, $1 \times$ PCR buffer, dNTPs of $2 \mu \mathrm{M}$ each, $1 \mu \mathrm{M} \mathrm{MgSO}_{4}, 5 \mu \mathrm{M}$ primer, and $0.2 \mathrm{U}$ of DNA polymerase (KOD plus, Toyobo Ltd. Tokyo), using a GeneAmp PCR system 9700 (Applied Biosystems, Foster, CA, U.S.A.). The PCR conditions were $94^{\circ} \mathrm{C}$ for $2 \mathrm{~min}$, followed by 30 cycles of $94^{\circ} \mathrm{C}$ for $30 \mathrm{~s}, 55^{\circ} \mathrm{C}$ for $30 \mathrm{~s}, 72^{\circ} \mathrm{C}$ for $1 \mathrm{~min}$, and final extension at $72^{\circ} \mathrm{C}$ for $7 \mathrm{~min}$. The PCR products were analyzed by electrophoresis on $3 \%$ Metaphor agarose (Cambrex Bioscience Rockland, Inc., East Rutherford, NJ, U.S.A.). The map position for the Ljsym105 locus was calculated from the recombination events.

\section{ACKNOWLEDGMENTS}

We thank S. Sato of Kazusa DNA Research Institute for providing information about DNA markers and R. W. Ridge of the International Christian University for critical reading of the manuscript. This work was supported by a fund of Core Research for Evolutional Science and Technology (CREST) from Japan Science and Technology Agency.

\section{LITERATURE CITED}

Ané, J. M., Kiss, G. B., Riely, B. K., Penmetsa, R. V., Oldroyd, G. E. D., Ayax, C., Levy, J., Debelle, F., Baek, J. M., Kalo, P., Rosenberg, C., Roe, B. A., Long, S. R., Denarie, J., and Cook, D. R. 2004. Medicago truncatula DMI1 required for bacterial and fungal symbioses in legumes. Science 303:1364-1367.

Asamizu, E., Nakamura, Y., Sato, S., and Tabata, S. 2005. Comparison of the transcript profiles from the root and the nodulating root of the model legume Lotus japonicus by serial analysis of gene expression. Mol. Plant-Microbe Interact. 18:487-498.

Banba, M., Siddique, A.-B. M., Kouchi, H., Izui, K., and Hata, S. 2001. Lotus japonicus forms early senescent root nodules with Rhizobium etli. Mol. Plant-Microbe Interact. 14:173-180.

Bénaben, V., Duc, G., Lefebvre, V., and Huguet, T. 1995. TE7, an inefficient symbiotic mutant of Medicago truncatula Gaertn. cv. Jemalong. Plant Physiol. 107:53-62.

Bensadoun, A., and Weinstein, D. 1976. Assay of proteins in the presence of interfering materials. Anal. Biochem. 70:241-250.

Bisseling, T., Moen, A. A., van den Bos, R. C., and van Kammen, A. 1980. The sequence of appearance of leghaemoglobin and nitrogenase components I and II in root nodules of Pisum sativum L. J. Gen. Microbiol. 118:377- 381

Colebatch, G., Desbrosses, G., Ott, T., Krusell, L., Montanari, O., Kloska, 
S., Kopka, J., and Udvardi, M. K. 2004. Global changes in transcription orchestrate metabolic differentiation during symbiotic nitrogen fixation in Lotus japonicus. Plant J. 39:487-512.

Colebatch, G., Kloska, S., Trevaskis, B., Freund, S., Altmann, T., and Udvardi, M. K. 2002. Novel aspects of symbiotic nitrogen fixation uncovered by transcript profiling with cDNA arrays. Mol. Plant-Microbe Interact. 15:411-420.

El Yahyaoui, F., Kuster, H., Ben Amor, B., Hohnjec, N., Puhler, A., Becker, A., Gougy, J., Vernie, T., Gough, C., Niebel, A., Godiard, L., and Gamas, P. 2004. Expression profiling in Medicago truncatula identifies more than 750 genes differentially expressed during nodulation, including many potential regulators of the symbiotic program. Plant Physiol. 136:3159-3176.

Endré, G., Kereszt, A., Kevei, Z., Mihacea, S., Kalo, P., and Kiss, G. B 2002. A receptor kinase gene regulating symbiotic nodule development. Nature 417:962-966.

Gamborg, O. L., and Wetter, L. R. 1975. Plant Tissue Culture Methods National Research Council of Canada, Saskatoon, Canada.

Hayashi, M., Miyahara, A., Sato, S., Kato, T., Yoshikawa, M., Taketa, M., Hayashi, M., Pedrosa, A., Onda, R., Imaizumi-Anraku, H., Bachmair, A., Sandal, N., Stougaard, J., Murooka, Y., Tabata, S., Kawasaki, S., Kawaguchi, M., and Harada, K. 2001. Construction of a genetic linkage map of the model legume Lotus japonicus using an intraspecific $\mathrm{F}_{2}$ population. DNA Res. 8:301-310.

Imaizumi-Anraku, H., Takeda, N., Charpentier, M., Perry, J., Miwa, H., Umehara, Y., Kouchi, H., Murakami, Y., Mulder, L., Vickers, K., Pike, J., Allan Downie, J., Wang, T., Sato, S., Asamizu, E., Tabata, S., Yoshikawa, M., Murooka, Y., Wu, G. J., Kawaguchi, M., Kawasaki, S., Parniske, M., and Hayashi, M. 2005. Plastid proteins crucial for symbiotic fungal and bacterial entry into plant roots. Nature 433:527-531.

Imaizumi-Anraku, H., Kawaguchi, M., Koiwa, H., Akao, S., and Syono, K. 1997. Two ineffective-nodulating mutants of Lotus japonicus-Different phenotypes caused by the blockage of endocytotic bacterial release and nodule maturation. Plant Cell Physiol. 38:871-881.

Kawaguchi, M., Imaizumi-Anraku, H., Koiwa, H., Niwa, S., Ikuta, A., Syono, K., and Akao, S. 2002. Root, root hair, and symbiotic mutants of the model legume Lotus japonicus. Mol. Plant-Microbe Interact. 15:1726.

Kouchi, H., Shimomura, K., Hata, S., Hirota, A., Wu, G. J., Kumagai, H., Tajima, S., Suganuma, N., Suzuki, A., Aoki, T., Hayashi, M., Yokoyama, T., Ohyama, T., Asamizu, E., Kuwata, C., Shibata, D., and Tabata, S. 2004. Large-scale analysis of gene expression profiles during early stages of root nodule formation in a model legume, Lotus japonicus. DNA Res. 11:263-274.

Kouchi, H., Fukai, K., and Kihara, A. 1991. Metabolism of glutamate and aspartate in bacteroids isolated from soybean root nodules. J. Gen. Microbiol. 137:2901-2910.

Krusell, L., Krause, K., Ott, T., Desbrosses, G., Kramer, U., Sato, S., Nakamura, Y., Tabata, S., James, E. K., Sandal, N., Stougaard, J., Kawaguchi, M., Miyamoto, A., Suganuma, N., and Udvardi, M. K. 2005. The sulfate transporter SST1 is crucial for symbiotic nitrogen fixation in Lotus japonicus root nodules. Plant Cell 17:1625-1636.

Laemmli, U. K. 1970. Cleavage of structural proteins during the assembly of the head of bacteriophage T4. Nature 227:680-685.

Levy, J., Bres, C., Geurts, R., Chalhoub, B., Kulikova, O., Duc, G., Journet, E. P., Ane, J. M., Lauber, E., Bisseling, t., Denarie, J., Rosenberg, C., and Debelle, F. 2004. A putative $\mathrm{Ca}^{2+}$ and calmodulin- dependent protein kinase required for bacterial and fungal symbioses. Science 303:1361-1363.

Limpens, E., Franken, C., Smit, P., Willemse, J., Bisseling, T., and Geurts, R. 2003. LysM domain receptor kinases regulating Rhizobial nod factor-induced infection. Science 302:630-633.

Madsen, E. B., Madsen, L. H., Radutolu, S., Olbryt, M., Rakwalska, M., Szczyglowski, K., Sato, S., Kaneko, T., Tabata, S., Sandal, N., and Stougaard, J. 2003. A receptor kinase gene of the LysM type is involved in legume perception of rhizobial signals. Nature 425:637-640.

Morzhina, E. V., Tsyganov, V. E., Borisov, A. Y., Lebsky, V. K., and Tikhonovich, I. A. 2000. Four developmental stages identified by genetic dissection of pea (Pisum sativum L.) root nodule morphogenesis. Plant Sci. 155:75-83

Murray, M. G., and Thompson, W. F. 1980. Rapid isolation of high molecular weight plant DNA. Nucleic Acids Res. 8:4321-4325.

Nakamura, Y., Kaneko, T., Asamizu, E., Kato, T., Sato, S., and Tabata, S. 2002. Structural analysis of a Lotus japonicus genome. II. Sequence features and mapping of sixty five TAC clones which cover the $6.5 \mathrm{Mb}$ regions of the genome. DNA Res. 9:63-70.

Novak, K., Pesina, K., Nebesarova, J., Skrdleta, V., Lisa, L., and Nasinec, V. 1995. Symbiotic tissue degradation pattern in the ineffective nodules of three nodulation mutants of pea (Pisum sativum L.). Ann. Bot. $76: 303-313$
Radutoiu, S., Madsen, L. H., Madsen, E. B., Felle, H. H., Umehara, Y. Grønlund, M., Sato, S., Nakamura, Y., Tabata, S., Sandal, N., and Stougaard, J. 2003. Plant recognition of symbiotic bacteria requires two LysM receptor-like kinases. Nature 425:585-592.

Ramirez, M., Graham, M. A., Blanco-Lopez, L., Silvente, S., MedranoSoto, A., Blair, M. W., Hernandez, G., Vance, C. P., and Lara, M. 2005. Sequencing and analysis of common bean ESTs. Building a foundation for functional genomics. Plant Physiol. 137:1211-1227.

Sagan, M., deLarambergue, H., and Morandi, D. 1998. Genetic analysis of symbiosis mutants in Medicago truncatula. Pages 317-318 in: Biological Nitrogen Fixtion for the 21st Century. C Elmerich, A Kondorosi, W. E. Newton, eds, Kluwer Academic Publishers, The Netherlands.

Sagan, M., Morandi, D., Tarenghi, E., and Duc, G. 1995. Selection of nodulation and mycorrhizal mutants in the model plant Medicago truncatula (Gaertn.) after gamma-ray mutagenesis. Plant Sci. 111:63-71.

Sandal, N., Petersen, T. R., Murray, J., Umehara, Y., Karas, B., Yano, K., Kumagai, H., Yoshikawa, M., Saito, K., Hayashi, M., Murakami, Y., Wang, X., Hakoyama, T., Imaizumi-Anraku, H., Sato, S., Kato, T., Chen, W., Hossain, M. S., Shibata, S., Wang, T., Yokota, K., Larsen, K., Kanamori, N., Madsen, E., Radutoiu, S., Madsen, L. H., Radu, T. G., Krusell, L., Ooki, Y., Banba, M., Betti, M., Rispail, N., Skøt, L., Tuck, E., Perry, J., Yoshida, S., Vickers, K., Pike, J., Mulder, L., Charpentier, M., Müller, J., Ohtomo, R., Kojima, T., Ando, S., Marquez, A. J., Gresshoff, P. M., Harada, K., Webb, J., Hata, S., Suganuma, N., Kouchi, H., Kawasaki, S., Tabata, S., Hayashi, M., Parniske, M., Szczyglowski, K., Kawaguchi, M., and Stougaard, J. 2006. Genetics of symbiosis in Lotus japonicus: Recombinant inbred lines, comparative genetic maps, and map position of 35 symbiotic loci. Mol. Plant-Microbe Interact. 19:80-91.

Sato, S., Kaneko, T., Nakamura, Y., Asamizu, E., Kato, T., and Tabata, S. 2001. Structural analysis of a Lotus japonicus genome. I. Sequence features and mapping of fifty six TAC clones which cover the $5.4 \mathrm{Mb}$ regions of the genome. DNA Res. 6:311-318.

Schauser, L., Handberg, K., Sandal, N., Stiller, J., Thykjear, T., Pajuelo, E., Nielsen, A., and Stougaard, J. 1998. Symbiotic mutants deficient in nodule establishment identified after T-DNA transformation of Lotus japonicus. Mol. Gen. Genet. 259:414-423.

Spaink, H. P., and Lugtenberg, B. J. J. 1994. Role of rhizobial lipo-chitin oligosaccharide signal molecules in root nodule organogenesis. Plant Mol. Biol. 26:1413-1422.

Stiller, J., Martirani, L., Tuppale, S., Chian, R., Chiurazzi, M., and Gresshoff, P. 1997. High frequency transformation and regeneration of transgenic plants in the model legume Lotus japonicus. J. Exp. Bot. 48:1357-1365.

Stracke, S., Kistner, C., Yoshida, S., Mulder, L., Sato, S., Kaneko, T., Tabata, S., Sandal, N., Stougaard, J., Szczyglowski, K., and Parniske, M. 2002. A plant receptor-like kinase required for both bacterial and fungal symbiosis. Nature 417:959-962.

Suganuma, N. 1999. Host plant genes affecting nitrogen fixing activity in legume nodules. Curr. Top. Plant Biol. 1:145-149.

Suganuma, N., Nakamura, Y., Yamamoto, M., Ohta, T., Koiwa, H., Akao, S., and Kawaguchi, M. 2003. The Lotus japonicus Sen1 gene controls rhizobial differentiation into nitrogen-fixing bacteroids in nodules. Mol Genet. Genomics 269:312-320.

Suganuma, N., Sonoda, N., Nakane, C., Hayashi, K., Hayashi, T., Tamaoki, M., and Kouchi, H. 1998. Bacteroids isolated from ineffective nodules of Pisum sativum mutant E135 (sym13) lack nitrogenase activity but contain the two protein contents of nitrogenase. Plant Cell Physiol. 39:1093-1098.

Suganuma, N., Tamoki, M., and Kouchi, H. 1995. Expression of nodulin genes in plant-determined ineffective nodules of pea. Plant Mol. Biol. 28:1027-1038

Szczyglowski, K., Shaw, R. S., Wopereis, J., Copeland, S., Hamburger, D., Kasiborski, B., Dazzo, F. B., and de Bruijn, F. J. 1998. Nodule organogenesis and symbiotic mutants of the model legume Lotus japonicus. Mol. Plant-Microbe Interact. 11:684-697.

Tian, A.G., Wang, J., Cui, P., Han, Y. J., Xu, H., Cong, L. J., Huang, X. G., Wang, X. L., Jiao, Y. Z., Wang, B. J., Wang, Y. J., Zhang, J. S., and Chen, S. Y. 2004. Characterization of soybean genomic features by analysis of its expressed sequence tags. Theor. Appl. Genet 108:903-913.

Uchiumi, T., Owada, T., Itakura, M., Mitsui, H., Nukui, N., Dawadi, P., Kaneko, T., Yokoyama, T., Tejima, K., Saeki, K., Oomori, H., Hayashi, M., Maekawa, T., Sriprang, R., Murooka, Y., Tajima, S., Shimomura, K., Nomura, M., Suzuki, A., Shimoda, Y., Shioya, K., Abe, M., and Minamisawa, K. 2004. Expression islands clustered on symbiosis island of Mesorhizobium loti genome. J. Bacteriol. 186:2439-2448.

\section{AUTHOR RECOMMENDED INTERNET RESOURCE}

ImageJ software ver. 1.34s website: rsb.info.nih.gov/ij 